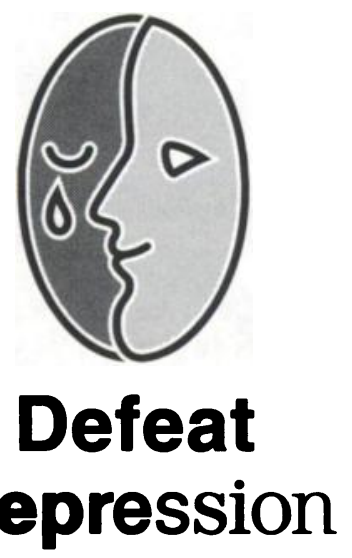

\title{
Management of depression in the elderly within primary care
}

The Defeat Depression Campaign Scientific Advisory Committee, chaired by Professor E. S. Paykel, has approved several research projects being conducted by members of the College in the area of depression and primary care. The preliminary findings of a project being done by Martin Orrell, Elizabeth Collins and Cornelius Katona, University College Hospital and Middlesex School of Medicine, into 'Management of Depression in the Elderly within Primary Care' are described below.

This study aims to investigate the attitudes of doctors towards the management of depression in the elderly, and to evaluate a teaching package for general practitioners on the assessment and management of depression in the elderly. Five catchment areas were selected to include inner city, urban and rural localities. The general practitioners from each area were sent a questionnaire comprising questions on their use of antidepressants, knowledge of psychological treatments, attitudes towards ageing and depression and details of their practice and training. The doctors also answered questions on three vignettes of elderly people with depression and which drug they would use and why. The questionnaire was also sent to a sample of trainee psychiatrists and consultants in old age psychiatry, and $\mathrm{Dr}$ Bob Baldwin has been using it with consultant geriatricians. A proportion of general practitioners subse- quently attended a training course on the management of depression in the elderly which was evaluated using a follow-up questionnaire. Seventy-two questionnaires have been received from the consultant psychiatrists (response rate $77 \%$ ) and 34 from trainee psychiatrists (response rate $74 \%$ ). So far 360 have been received from general practitioners and 72 from consultant geriatricians but as questionnaires are still coming in the final response rates are not yet available. Preliminary results have been presented at two conferences including the joint Royal College/ British Geriatric Society meeting in November 1992.

The findings should provide a better idea of the current knowledge and clinical practice of general practitioners in the management of depression in the elderly in comparison with psychiatrists and geriatricians. If general practitioners manage depression inappropriately, in that they do not give medication, give it in the wrong dose, or do not increase it to a therapeutic level, this has serious implications for the health of patients and their quality of life. In addition, if doctors do not know which drugs are comparatively safe in overdosage, or with certain physical conditions in the elderly, this could be dangerous. Equally, general practitioners may not know which psychological treatments are effective. If the training programme is successful they would learn how to manage depression more effectively and appropriately which would have widespread benefits for patient care. 